\title{
Tripled Fixed Points of Multivalued Nonlinear Contraction Mappings in Partially Ordered Metric Spaces
}

\author{
Mujahid Abbas, ${ }^{1}$ Hassen Aydi, ${ }^{2}$ and Erdal Karapinar ${ }^{3}$ \\ ${ }^{1}$ Department of Mathematics, Lahore University of Management Sciences, 54792 Lahore, Pakistan \\ ${ }^{2}$ Institut Supérieur d'Informatique et des Technologies de Comminucation de Hammam Sousse, \\ Université de Sousse, Route GP1, 4011 Hammam Sousse, Tunisia \\ ${ }^{3}$ Department of Mathematics, Atilim University, Incek, 06836 Ankara, Turkey
}

Correspondence should be addressed to Hassen Aydi, hassen.aydi@isima.rnu.tn

Received 5 August 2011; Accepted 19 October 2011

Academic Editor: Yong Zhou

Copyright (C) 2011 Mujahid Abbas et al. This is an open access article distributed under the Creative Commons Attribution License, which permits unrestricted use, distribution, and reproduction in any medium, provided the original work is properly cited.

Berinde and Borcut (2011), introduced the concept of tripled fixed point for single mappings in partially ordered metric spaces. Samet and Vetro (2011) established some coupled fixed point theorems for multivalued nonlinear contraction mappings in partially ordered metric spaces. In this paper, we obtain existence of tripled fixed point of multivalued nonlinear contraction mappings in the framework of partially ordered metric spaces. Also, we give an example.

\section{Introduction and Preliminaries}

Let $(X, d)$ be a metric space. Consistent with [1], we denote by $C B(X)$ the family of all nonempty closed bounded and nonempty closed subsets of $X$. Let $\mathrm{CL}(X)=\{A \subset X: A \neq \emptyset$ and $A=\bar{A}\}$, where $\bar{A}$ denotes the closure of $A$ in $X$. For $A, B \in C B(X)$, and $x \in X$, set $D(x, A):=\inf \{d(x, a): a \in A\}$. We define a Hausdorff metric $H$ on $C B(X)$ by

$$
H(A, B):=\max \left\{\sup _{a \in A} D(a, B), \sup _{b \in B} D(b, A)\right\}
$$

A point $x \in K$ is called a fixed point of $T$ if $x \in T x$.

The study of fixed points for multivalued contractions and nonexpansive maps using the Hausdorff metric was initiated by Markin [2]. Later, an interesting and rich fixed point 
theory for such maps was developed. Several authors studied the problem of existence of fixed point of multivalued mappings satisfying different contractive conditions (see, e.g., [310]). The theory of multivalued maps has application in control theory, convex optimization, differential equations, and economics.

Existence of fixed points in ordered metric spaces has been initiated in 2004 by Ran and Reurings [11], further studied by Nieto and Rodríguez-López [12]. Samet and Vetro [13] introduced the notion of fixed point of $N$ order in case of single-valued mappings. In particular for $N=3$ (tripled case), we have the following definition.

Definition 1.1 (see, e.g., [13]). An element $(x, y, z) \in X^{3}$ is called a tripled fixed point of a mapping $F: X^{3} \rightarrow X$ if and only if

$$
x=F(x, y, z), \quad y=F(y, z, x), \quad z=F(z, x, y) .
$$

Recently, Berinde and Borcut [14] established the existence of tripled fixed point of single-valued mappings in partially ordered metric spaces. The aim of this paper is to initiate the study of tripled fixed point of multivalued mappings in the framework of partially ordered metric spaces which in turn extend and strengthen various known results $[5,15]$.

\section{Tripled Fixed Point Results for Multivalued Mappings}

First, we introduce the following concepts.

Definition 2.1. An element $(x, y, z) \in X^{3}$ is called a tripled fixed point of $F: X^{3} \rightarrow \mathrm{CL}(X)$ if

$$
x \in F(x, y, z), \quad y \in F(y, z, x), \quad z \in F(z, x, y) .
$$

Definition 2.2. A mapping $f: X^{3} \rightarrow \mathbb{R}$ is called lower semicontinuous if, for any sequences $\left\{x_{n}\right\},\left\{y_{n}\right\},\left\{z_{n}\right\}$ in $X$ and $(x, y, z) \in X^{3}$, one has

$$
\lim _{n \rightarrow \infty}\left(x_{n}, y_{n}, z_{n}\right)=(x, y, z) \Longrightarrow f(x, y, z) \leq \liminf _{n \rightarrow \infty}\left(x_{n}, y_{n}, z_{n}\right)
$$

Let $(X, d)$ be a metric space endowed with a partial order $\leq$ and $T: X \rightarrow X$. Define the set $\Psi \subset X^{3}$ by

$$
\Psi=\left\{(x, y, z) \in X^{3}: T(x) \preceq T(y) \preceq T(z)\right\}
$$

Definition 2.3. A mapping $F: X^{3} \rightarrow X$ is said to have a $\Psi$-property if

$$
(x, y, z) \in \Psi \Longrightarrow F(x, y, z) \times F(y, z, x) \times F(z, y, x) \subset \Psi
$$


We give some examples to illustrate Definition 2.3.

Example 2.4. Let $X=\mathbb{R}$ be endowed with the usual order $\leq$, and $T: X \rightarrow X$. Define $F: X^{3} \rightarrow$ $\mathrm{CL}(\mathrm{X})$ by

$$
F(x, y, z)=\{x\} \quad \forall x, y, z \in \mathbb{R} .
$$

Obviously, $F$ has the $\Psi$-property.

Example 2.5. Let $X=\mathbb{R}^{+}$be endowed with the usual order $\leq$, and let $T: X \rightarrow X$ be defined by $T x=\exp (x)$. Define $F: X^{3} \rightarrow \mathrm{CL}(X)$ by

$$
F(x, y, z)=\{x+z\} \quad \forall x, y, z \in \mathbb{R}^{+} .
$$

We have $\Psi=\left\{(x, y, z) \in X^{3}, \exp (x) \leq \exp (y) \leq \exp (z)\right\}$. Moreover, $F$ has the $\Psi$-property.

Now, we prove the following theorem.

Theorem 2.6. Let $(X, d)$ be a complete metric space endowed with a partial order $\leq$ and $\Psi \neq \emptyset$; that is, there exists $\left(x_{0}, y_{0}, z_{0}\right) \in \Psi$. Suppose that $F: X^{3} \rightarrow \mathrm{CL}(X)$ has a $\Psi$-property such that $f: X^{3} \rightarrow$ $[0, \infty)$ given by

$$
f(x, y, z)=D(x, F(x, y, z))+D(y, F(y, z, x))+D(z, F(z, x, y)) \quad \forall x, y, z \in X
$$

is lower semicontinuous and there exists a function $\phi:[0, \infty) \rightarrow[M, 1), 0<M<1$, satisfying

$$
\limsup _{r \rightarrow t^{+}} \phi(r)<1 \text { for each } t \in[0, \infty) \text {. }
$$

If for any $(x, y, z) \in \Psi$ there exist $u \in F(x, y, z), v \in F(y, z, x)$, and $w \in F(z, y, x)$ with

$$
\sqrt{\phi(f(x, y, z))}[d(x, u)+d(y, v)+d(z, w)] \leq f(x, y, z)
$$

such that

$$
f(u, v, w) \leq \phi(f(x, y, z))[d(x, u)+d(y, v)+d(z, w)]
$$

then $F$ has a tripled fixed point.

Proof. By our assumption, $\phi(f(x, y, z))<1$ for each $(x, y, z) \in X^{3}$. Hence, for any $(x, y, z) \in$ $X^{3}$, there exist $u \in F(x, y, z), v \in F(y, z, x)$, and $w \in F(z, x, y)$ satisfying

$$
\begin{aligned}
& \sqrt{\phi(f(x, y, z))} d(x, u) \leq D(x, F(x, y, z)), \\
& \sqrt{\phi(f(x, y, z))} d(y, v) \leq D(y, F(y, z, x)), \\
& \sqrt{\phi(f(x, y, z))} d(z, w) \leq D(z, F(z, x, y)) .
\end{aligned}
$$


Let $\left(x_{0}, y_{0}, z_{0}\right)$ be an arbitrary point in $\Psi$. By (2.9) and (2.10), we can choose $x_{1} \in F\left(x_{0}, y_{0}, z_{0}\right)$, $y_{1} \in F\left(y_{0}, z_{0}, x_{0}\right)$, and $z_{1} \in F\left(z_{0}, x_{0}, y_{0}\right)$ satisfying

$$
\sqrt{\phi\left(f\left(x_{0}, y_{0}, z_{0}\right)\right)}\left[d\left(x_{0}, x_{1}\right)+d\left(y_{0}, y_{1}\right)+d\left(z_{0}, z_{1}\right)\right] \leq f\left(x_{0}, y_{0}, z_{0}\right)
$$

such that

$$
f\left(x_{1}, y_{1}, z_{1}\right) \leq \phi\left(f\left(x_{0}, y_{0}, z_{0}\right)\right)\left[d\left(x_{0}, x_{1}\right)+d\left(y_{0}, y_{1}\right)+d\left(z_{0}, z_{1}\right)\right]
$$

By (2.12) and (2.13), we obtain

$$
\begin{aligned}
f\left(x_{1}, y_{1}, z_{1}\right) & \leq \phi\left(f\left(x_{0}, y_{0}, z_{0}\right)\right)\left[d\left(x_{0}, x_{1}\right)+d\left(y_{0}, y_{1}\right)+d\left(z_{0}, z_{1}\right)\right] \\
& \leq \sqrt{\phi\left(f\left(x_{0}, y_{0}, z_{0}\right)\right)}\left(\sqrt{\phi\left(f\left(x_{0}, y_{0}, z_{0}\right)\right)}\left[d\left(x_{0}, x_{1}\right)+d\left(y_{0}, y_{1}\right)+d\left(z_{0}, z_{1}\right)\right]\right) \\
& \leq \sqrt{\phi\left(f\left(x_{0}, y_{0}, z_{0}\right)\right)} f\left(x_{0}, y_{0}, z_{0}\right) .
\end{aligned}
$$

Thus,

$$
f\left(x_{1}, y_{1}, z_{1}\right) \leq \sqrt{\phi\left(f\left(x_{0}, y_{0}, z_{0}\right)\right)} f\left(x_{0}, y_{0}, z_{0}\right)
$$

Since $F$ has a $\Psi$-property and $\left(x_{0}, y_{0}, z_{0}\right) \in \Psi$, so we have

$$
F\left(x_{0}, y_{0}, z_{0}\right) \times F\left(y_{0}, z_{0}, x_{0}\right) \times F\left(z_{0}, x_{0}, y_{0}\right) \subset \Psi
$$

which implies that $\left(x_{1}, y_{1}, z_{1}\right) \in \Psi$.

Again by (2.9) and (2.10), we can choose $x_{2} \in F\left(x_{1}, y_{1}, z_{1}\right), y_{2} \in F\left(y_{1}, z_{1}, x_{1}\right)$, and $z_{2} \in F\left(z_{1}, x_{1}, y_{1}\right)$ satisfying

$$
\sqrt{\phi\left(f\left(x_{1}, y_{1}, z_{1}\right)\right)}\left[d\left(x_{1}, x_{2}\right)+d\left(y_{1}, y_{2}\right)+d\left(z_{1}, z_{2}\right)\right] \leq f\left(x_{1}, y_{1}, z_{1}\right)
$$

such that

$$
f\left(x_{2}, y_{2}, z_{2}\right) \leq \phi\left(f\left(x_{1}, y_{1}, z_{1}\right)\right)\left[d\left(x_{1}, x_{2}\right)+d\left(y_{1}, y_{2}\right)+d\left(z_{1}, z_{2}\right)\right]
$$

Thus, we have

$$
f\left(x_{2}, y_{2}, z_{2}\right) \leq \sqrt{\phi\left(f\left(x_{1}, y_{1}, z_{1}\right)\right)} f\left(x_{1}, y_{1}, z_{1}\right)
$$

and $\left(x_{2}, y_{2}, z_{2}\right) \in \Psi$.

Continuing this process, we can choose sequences $\left\{x_{n}\right\},\left\{y_{n}\right\},\left\{z_{n}\right\}$ in $X$ such that for each $n \in \mathbb{N}$ with $\left(x_{n}, y_{n}, z_{n}\right) \in \Psi$. 


$$
\begin{gathered}
x_{n+1} \in F\left(x_{n}, y_{n}, z_{n}\right), y_{n+1} \in F\left(y_{n}, z_{n}, x_{n}\right) \text { and } z_{n+1} \in F\left(z_{n}, x_{n}, y_{n}\right) \text { satisfying } \\
\sqrt{\phi\left(f\left(x_{n}, y_{n}, z_{n}\right)\right)}\left[d\left(x_{n}, x_{n+1}\right)+d\left(y_{n}, y_{n+1}\right)+d\left(z_{n}, z_{n+1}\right)\right] \leq f\left(x_{n}, y_{n}, z_{n}\right)
\end{gathered}
$$

such that

$$
f\left(x_{n+1}, y_{n+1}, z_{n+1}\right) \leq \phi\left(f\left(x_{n}, y_{n}, z_{n}\right)\right)\left[d\left(x_{n}, x_{n+1}\right)+d\left(y_{n}, y_{n+1}\right)+d\left(z_{n}, z_{n+1}\right)\right]
$$

Hence, we obtain

$$
f\left(x_{n+1}, y_{n+1}, z_{n+1}\right) \leq \sqrt{\phi\left(f\left(x_{n}, y_{n}, z_{n}\right)\right)} f\left(x_{n}, y_{n}, z_{n}\right)
$$

with $\left(x_{n+1}, y_{n+1}, z_{n+1}\right) \in \Psi$. We claim that $f\left(x_{n}, y_{n}, z_{n}\right) \rightarrow 0$ as $n \rightarrow \infty$. If $f\left(x_{n}, y_{n}, z_{n}\right)=0$ for some $n \in \mathbb{N}$, then $D\left(x_{n}, F\left(x_{n}, y_{n}, z_{n}\right)\right)=0$ implies that $x_{n} \in \overline{F\left(x_{n}, y_{n}, z_{n}\right)}=F\left(x_{n}, y_{n}\right.$, $\left.z_{n}\right)$. Analogously, $D\left(y_{n}, F\left(y_{n}, z_{n}, x_{n}\right)\right)=0$ implies that $y_{n} \in F\left(y_{n}, z_{n}, x_{n}\right)$ and $D\left(z_{n}\right.$, $\left.F\left(z_{n}, y_{n}, x_{n}\right)\right)=0$ implies that $z_{n} \in F\left(z_{n}, y_{n}, x_{n}\right)$. Hence, $\left(x_{n}, y_{n}, z_{n}\right)$ becomes a tripled fixed point of $F$ for such $n$ and the result follows. Suppose that $f\left(x_{n}, y_{n}, z_{n}\right)>0$ for all $n \in \mathbb{N}$.

Using (2.22) and $\phi(t)<1$, we conclude that $\left\{f\left(x_{n}, y_{n}, z_{n}\right)\right\}$ is a decreasing sequence of positive real numbers. Thus, there exists a $\delta \geq 0$ such that

$$
\lim _{n \rightarrow \infty} f\left(x_{n}, y_{n}, z_{n}\right)=\delta
$$

We will show that $\delta=0$. Assume on contrary that $\delta>0$. Letting $n \rightarrow \infty$ in (2.22) and by assumption (2.8), we obtain

$$
\delta \leq \limsup _{f\left(x_{n}, y_{n}, z_{n}\right) \rightarrow \delta^{+}} \sqrt{\phi\left(f\left(x_{n}, y_{n}, z_{n}\right)\right)} \delta<\delta
$$

a contradiction. Hence,

$$
\lim _{n \rightarrow \infty} f\left(x_{n}, y_{n}, z_{n}\right)=0^{+}
$$

Now, we prove that $\left\{x_{n}\right\},\left\{y_{n}\right\},\left\{z_{n}\right\} \subset X$ are Cauchy sequences in $(X, d)$. Assume that

$$
\alpha=\limsup _{f\left(x_{n}, y_{n}, z_{n}\right) \rightarrow 0^{+}} \sqrt{\phi\left(f\left(x_{n}, y_{n}, z_{n}\right)\right)} .
$$

By (2.8), we conclude that $\alpha<1$. Let $k$ be a real number such that $\alpha<k<1$. Thus, there exists $n_{0} \in \mathbb{N}$ such that

$$
\sqrt{\phi\left(f\left(x_{n}, y_{n}, z_{n}\right)\right)}<k \text { for each } n \geq n_{0}
$$


Using (2.22), we obtain

$$
f\left(x_{n+1}, y_{n+1}, z_{n+1}\right)<k f\left(x_{n}, y_{n}, z_{n}\right) \text { for each } n \geq n_{0}
$$

By mathematical induction,

$$
f\left(x_{n+1}, y_{n+1}, z_{n+1}\right)<k^{n+1-n_{0}} f\left(x_{n_{0}}, y_{n_{0}}, z_{n_{0}}\right) \text { for each } n \geq n_{0}
$$

Since $\phi(t) \geq M>0$ for all $t \geq 0$ so (2.20), and (2.29) gives that

$$
\left[d\left(x_{n}, x_{n+1}\right)+d\left(y_{n}, y_{n+1}\right)+d\left(z_{n}, z_{n+1}\right)\right]<\frac{k^{n-n_{0}}}{\sqrt{M}} f\left(x_{n_{0}}, y_{n_{0}}, z_{n_{0}}\right) \quad \text { for each } n \geq n_{0}
$$

which yields that $\left\{x_{n}\right\},\left\{y_{n}\right\},\left\{z_{n}\right\} \subset X$ are Cauchy sequences in $X$. Since $X$ is complete, there exists $(a, b, c) \in X^{3}$ such that

$$
\lim _{n \rightarrow \infty} x_{n}=a, \quad \lim _{n \rightarrow \infty} y_{n}=b, \quad \lim _{n \rightarrow \infty} z_{n}=\mathrm{c} .
$$

Finally, we show that $(a, b, c) \in X^{3}$ is tripled fixed point of $F$. As $f$ is lower semicontinuous, (2.25) implies that

$$
0 \leq f(a, b, c)=D(a, F(a, b, c))+D(b, F(b, c, a))+D(c, F(c, a, b)) \leq \liminf _{n \rightarrow \infty} f\left(x_{n}, y_{n}, z_{n}\right)=0
$$

Hence, $D(a, F(a, b, c))=D(b, F(b, c, a))=D(c, F(c, a, b))=0$ gives that $(a, b, c)$ is a tripled fixed point of $F$.

Theorem 2.7. Let $(X, d)$ be a complete metric space endowed with a partial order $\leq$ and $\Psi \neq \emptyset$; that is, there exists $\left(x_{0}, y_{0}, z_{0}\right) \in \Psi$. Suppose that $F: X^{3} \rightarrow \mathrm{CL}(X)$ has a $\Psi$-property such that function $f: X^{3} \rightarrow[0, \infty)$ defined by

$$
f(x, y, z)=D(x, F(x, y, z))+D(y, F(y, z, x))+D(z, F(z, x, y)) \quad \forall x, y, z \in X
$$

is lower semicontinuous and there exists a function $\phi:[0, \infty) \rightarrow[M, 1), 0<M<1$, satisfying

$$
\limsup _{r \rightarrow t^{+}} \phi(r)<1 \text { for each } t \in[0, \infty) \text {. }
$$

If for any $(x, y, z) \in \Psi$ there exist $u \in F(x, y, z), v \in F(y, z, x)$, and $w \in F(z, y, x)$ satisfying

$$
\sqrt{\phi(\Delta)} \Delta \leq D(x, f(x, y, z))+D(y, f(y, z, x))+D(z, f(z, x, y))
$$


such that

$$
D(u, f(u, v, w))+D(v, f(v, w, u))+D(w, f(w, u, v)) \leq \phi(\Delta) \Delta
$$

where $\Delta=\Delta((x, y, z),(u, v, w))=[d(x, u)+d(y, v)+d(z, w)]$, then $F$ admits a tripled fixed point.

Proof. By replacing $\phi(f(x, y, z))$ with $\phi([d(x, u)+d(y, v)+d(z, w)])$ in the proof of Theorem 2.6, we obtain sequences $\left\{x_{n}\right\},\left\{y_{n}\right\},\left\{z_{n}\right\} \subset X$ such that for each $n \in \mathbb{N}$ with

$$
\left(x_{n}, y_{n}, z_{n}\right) \in \Psi, \quad x_{n+1} \in F\left(x_{n}, y_{n}, z_{n}\right), \quad y_{n+1} \in F\left(y_{n}, z_{n}, x_{n}\right), \quad z_{n+1} \in F\left(z_{n}, x_{n}, y_{n}\right),
$$

such that

$$
\begin{aligned}
& \sqrt{\phi\left(\Delta_{n}\right)} \Delta_{n} \leq D\left(x_{n}, F\left(x_{n}, y_{n}, z_{n}\right)\right)+D\left(y_{n}, F\left(y_{n}, z_{n}, x_{n}\right)\right)+D\left(z_{n}, F\left(z_{n}, x_{n}, y_{n}\right)\right) \\
& D\left(x_{n+1}, F\left(x_{n+1}, y_{n+1}, z_{n+1}\right)\right)+D\left(y_{n+1}, F\left(y_{n+1}, z_{n+1}, x_{n+1}\right)\right)+D\left(z_{n+1}, F\left(z_{n+1}, x_{n+1}, y_{n+1}\right)\right) \\
& \leq \sqrt{\phi\left(\Delta_{n}\right)}\left(D\left(x_{n}, F\left(x_{n}, y_{n}, z_{n}\right)\right)+D\left(y_{n}, F\left(y_{n}, z_{n}, x_{n}\right)\right)+D\left(z_{n}, F\left(z_{n}, x_{n}, y_{n}\right)\right)\right),
\end{aligned}
$$

where

$$
\Delta_{n}=\Delta_{n}\left(\left(x_{n}, y_{n}, z_{n}\right),\left(x_{n+1}, y_{n+1}, z_{n+1}\right)\right)=d\left(x_{n}, x_{n+1}\right)+d\left(y_{n}, y_{n+1}\right)+d\left(z_{n}, z_{n+1}\right)
$$

Again, following arguments similar to those given in the proof of Theorem 2.6, we deduce that

$$
\left\{D\left(x_{n}, F\left(x_{n}, y_{n}, z_{n}\right)\right)+D\left(y_{n}, F\left(y_{n}, z_{n}, x_{n}\right)\right)+D\left(z_{n}, F\left(z_{n}, x_{n}, y_{n}\right)\right)\right\}
$$

is a decreasing sequence of real numbers. Thus, there exists a $\delta>0$ such that

$$
\lim _{n \rightarrow \infty} D\left(x_{n}, F\left(x_{n}, y_{n}, z_{n}\right)\right)+D\left(y_{n}, F\left(y_{n}, z_{n}, x_{n}\right)\right)+\left(z_{n}, F\left(z_{n}, x_{n}, y_{n}\right)\right)=\delta
$$

Now, we need to prove that $\left\{\Delta_{n}\right\}$ admits a subsequence converging to certain $\eta^{+}$for some $\eta \geq 0$. Since $\phi(t) \geq M>0$, using (2.38), we obtain

$$
\Delta_{n} \leq \frac{1}{\sqrt{a}}\left(D\left(x_{n}, F\left(x_{n}, y_{n}, z_{n}\right)\right)+D\left(y_{n}, F\left(y_{n}, z_{n}, x_{n}\right)\right)+D\left(z_{n}, F\left(z_{n}, x_{n}, y_{n}\right)\right)\right) .
$$

From (2.42) and (2.43), it is clear that the sequence

$$
\left\{D\left(x_{n}, F\left(x_{n}, y_{n}, z_{n}\right)\right)+D\left(y_{n}, F\left(y_{n}, z_{n}, x_{n}\right)\right)+D\left(z_{n}, F\left(z_{n}, x_{n}, y_{n}\right)\right)\right\}
$$


is bounded. Therefore, there is some $\theta \geq 0$ such that

$$
\liminf _{n \rightarrow+\infty} \Delta_{n}=\theta
$$

From (2.37), we have $x_{n+1} \in F\left(x_{n}, y_{n}, z_{n}\right), y_{n+1} \in F\left(y_{n}, z_{n}, x_{n}\right)$, and $z_{n+1} \in F\left(z_{n}, x_{n}, y_{n}\right)$,

$$
\Delta_{n} \geq D\left(x_{n}, F\left(x_{n}, y_{n}, z_{n}\right)\right)+D\left(y_{n}, F\left(y_{n}, z_{n}, x_{n}\right)\right)+D\left(z_{n}, F\left(z_{n}, x_{n}, y_{n}\right)\right) \text { for each } n \geq 0
$$

So comparing (2.42) to (2.45), we get that $\theta \geq \delta$. Now, we shall show that $\theta=\delta$. If $\delta=0$, then, by (2.42) and (2.43), we get $\theta=: \liminf _{n \rightarrow+\infty} \Delta_{n}=0$ and consequently $\theta=\delta=0$. Suppose that $\delta>0$. Assume on contrary that $\theta>\delta$. From (2.42) and (2.45), there is a positive integer $n_{0}$ such that

$$
\begin{gathered}
D\left(x_{n}, F\left(x_{n}, y_{n}, z_{n}\right)\right)+D\left(y_{n}, F\left(y_{n}, z_{n}, x_{n}\right)\right)+D\left(z_{n}, F\left(z_{n}, x_{n}, y_{n}\right)\right)<\delta+\frac{\theta-\delta}{4}, \\
\delta-\frac{\theta-\delta}{4}<\Delta_{n}
\end{gathered}
$$

for all $n \geq n_{0}$. We combine (2.38), (2.47) to (2.48) to obtain

$$
\begin{aligned}
\sqrt{\phi\left(\Delta_{n}\right)}\left(\delta-\frac{\theta-\delta}{4}\right) & \leq \sqrt{\phi\left(\Delta_{n}\right)} \Delta_{n} \\
& \leq D\left(x_{n}, F\left(x_{n}, y_{n}, z_{n}\right)\right)+D\left(y_{n}, F\left(y_{n}, z_{n}, x_{n}\right)\right)+D\left(z_{n}, F\left(z_{n}, x_{n}, y_{n}\right)\right) \\
& <\delta+\frac{\theta-\delta}{4}
\end{aligned}
$$

for all $n \geq n_{0}$. It follows that

$$
\sqrt{\phi\left(\Delta_{n}\right)} \leq \frac{\theta+3 \delta}{3 \theta+\delta} \quad \forall n \geq n_{0}
$$

By (2.39) and (2.50), we have

$$
\begin{array}{r}
D\left(x_{n+1}, F\left(x_{n+1}, y_{n+1}, z_{n+1}\right)\right)+D\left(y_{n+1}, F\left(y_{n+1}, z_{n+1}, x_{n+1}\right)\right)+D\left(z_{n+1}, F\left(z_{n+1}, x_{n+1}, y_{n+1}\right)\right) \\
\leq h\left(D\left(x_{n}, F\left(x_{n}, y_{n}, z_{n}\right)\right)+D\left(y_{n}, F\left(y_{n}, z_{n}, x_{n}\right)\right)+D\left(z_{n}, F\left(z_{n}, x_{n}, y_{n}\right)\right)\right) \quad \forall n \geq n_{0},
\end{array}
$$


where $h=(\theta+3 \delta) /(3 \theta+\delta)$. Since $\theta>\delta>0$, therefore $h<1$, so proceeding by induction and combining the above inequalities, it follows that

$$
\begin{aligned}
\delta \leq & D\left(x_{n_{0}+k_{0}}, F\left(x_{n_{0}+k_{0}}, y_{n_{0}+k_{0}}, z_{n_{0}+k_{0}}\right)\right)+D\left(y_{n_{0}+k_{0}}, F\left(y_{n_{0}+k_{0}}, z_{n_{0}+k_{0}}, x_{n_{0}+k_{0}}\right)\right) \\
& +D\left(z_{n_{0}+k_{0}}, F\left(z_{n_{0}+k_{0}}, x_{n_{0}+k_{0}}, y_{n_{0}+k_{0}}\right)\right) \\
\leq & h^{k_{0}}\left[D\left(x_{n_{0}}, F\left(x_{n_{0}}, y_{n_{0}}, z_{n_{0}}\right)\right)+D\left(y_{n_{0}}, F\left(y_{n_{0}}, z_{n_{0}}, x_{n_{0}}\right)\right)+D\left(z_{n_{0}}, F\left(z_{n_{0}}, x_{n_{0}}, y_{n_{0}}\right)\right)\right]<\delta,
\end{aligned}
$$

for a positive integer $k_{0}$. Then, we obtain a contradiction, so we must have $\theta=\delta$.

Now, we shall show that $\theta=0$. Since

$$
\theta=\delta \leq D\left(x_{n}, F\left(x_{n}, y_{n}, z_{n}\right)\right)+D\left(y_{n}, F\left(y_{n}, z_{n}, x_{n}\right)\right)+D\left(z_{n}, F\left(z_{n}, x_{n}, y_{n}\right)\right) \leq \Delta_{n}
$$

then we rewrite $(2.45)$ as

$$
\liminf _{n \rightarrow+\infty} \Delta_{n}=\theta^{+}
$$

Hence, there exists a subsequence $\left\{\Delta_{n_{k}}\right\}$ of $\left\{\Delta_{n}\right\}$ such that $\liminf _{k \rightarrow+\infty} \Delta_{n_{k}}=\theta^{+}$.

By (2.34), we have

$$
\limsup _{\Delta_{n_{k}} \rightarrow \theta^{+}} \sqrt{\phi\left(\Delta_{n_{k}}\right)}<1
$$

From (2.39), we obtain

$$
\begin{aligned}
& D\left(x_{n_{k}+1}, F\left(x_{n_{k}+1}, y_{n_{k}+1}, z_{n_{k}+1}\right)\right)+D\left(y_{n_{k}+1}, F\left(y_{n_{k}+1}, z_{n_{k}+1}, x_{n_{k}+1}\right)\right) \\
& \quad+D\left(z_{n_{k}+1}, F\left(z_{n_{k}+1}, x_{n_{k}+1}, y_{n_{k}+1}\right)\right) \\
& \leq \sqrt{\phi\left(\Delta_{n_{k}}\right)}\left(D\left(x_{n_{k}}, F\left(x_{n_{k}}, y_{n_{k}}, z_{n_{k}}\right)\right)+D\left(y_{n_{k}}, f\left(y_{n_{k}}, z_{n_{k}}, x_{n_{k}}\right)\right)+D\left(z_{n_{k}}, F\left(z_{n_{k}}, x_{n_{k}}, y_{n_{k}}\right)\right)\right) .
\end{aligned}
$$

Taking the limit as $k \rightarrow \infty$ and using (2.42), we have

$$
\begin{aligned}
& \delta=\limsup _{k \rightarrow+\infty}\left[D\left(x_{n_{k}+1}, F\left(x_{n_{k}+1}, y_{n_{k}+1}, z_{n_{k}+1}\right)\right)+D\left(y_{n_{k}+1}, F\left(y_{n_{k}+1}, z_{n_{k}+1}, x_{n_{k}+1}\right)\right)\right. \\
& \left.+D\left(z_{n_{k}+1}, f\left(z_{n_{k}+1}, x_{n_{k}+1}, y_{n_{k}+1}\right)\right)\right] \\
& \leq \limsup _{k \rightarrow+\infty}\left[\sqrt{\phi\left(\Delta_{n_{k}}\right)}\right]
\end{aligned}
$$




$$
\begin{aligned}
& \limsup _{k \rightarrow+\infty}\left(D\left(x_{n_{k}}, F\left(x_{n_{k}}, y_{n_{k}}, z_{n_{k}}\right)\right)+D\left(y_{n_{k}}, F\left(y_{n_{k}}, z_{n_{k}}, x_{n_{k}}\right)\right)+D\left(z_{n_{k}}, F\left(z_{n_{k}}, x_{n_{k}}, y_{n_{k}}\right)\right)\right) \\
& \quad=\left(\limsup _{\Delta_{n_{k}} \rightarrow \theta^{+}} \sqrt{\phi\left(\Delta_{n_{k}}\right)}\right) \delta .
\end{aligned}
$$

Assume that $\delta>0$, then from (2.57) we get that

$$
1 \leq \limsup _{\Delta_{n_{k}} \rightarrow \theta^{+}} \sqrt{\phi\left(\Delta_{n_{k}}\right)}
$$

a contradiction with respect to (2.55), so $\delta=0$. Now, from (2.39), and (2.42) we have

$$
\alpha=\limsup _{\Delta_{n} \rightarrow 0^{+}} \sqrt{\phi\left(\Delta_{n}\right)}<1 .
$$

The rest of the proof is similar to the proof of Theorem 2.6, so it is omitted.

We improved and corrected the example of Samet and Vetro [13].

Example 2.8. Let $X=[0,1]$, and let $d: X \times X \rightarrow[0, \infty)$ be the usual metric. Suppose that $T(x)=M$ for all $x \in[0,1]$ where $M$ is a constant in $[0,1]$, and $F: X^{3} \rightarrow \operatorname{CL}(X)$ is defined, for all $y, z \in X$ as follow:

$$
F(x, y, z)= \begin{cases}\left\{\frac{x^{2}}{4}\right\} & \text { if } x \in\left[0, \frac{15}{32}\right) \cup\left(\frac{15}{32}, 1\right], \\ \left\{\frac{15}{96}, \frac{1}{5}\right\} & \text { if } x=\frac{15}{32} .\end{cases}
$$

Obviously, $F$ has the $\Psi$-property. Set $\phi:[0, \infty) \rightarrow[0,1)$ :

$$
\phi(t)= \begin{cases}\frac{11}{12} t & \text { if } t \in\left[0, \frac{2}{3}\right] \\ \frac{10}{16} & \text { if } t \in\left(\frac{2}{3}, \infty\right) .\end{cases}
$$

Consider the function

$$
f(x, y, z)= \begin{cases}x+y+z-\frac{1}{4}\left(x^{2}+y^{2}+z^{2}\right) & \text { if } x, y, z \in\left[0, \frac{15}{32}\right) \cup\left(\frac{15}{32}, 1\right] \\ x+y-\frac{1}{4}\left(x^{2}+y^{2}\right)+\frac{43}{160} & \text { if } x, y \in\left[0, \frac{15}{32}\right) \cup\left(\frac{15}{32}, 1\right] \text { with } z=\frac{15}{32} \\ x-\frac{1}{4} x^{2}+\frac{86}{160} & \text { if } x, y \in\left[0, \frac{15}{32}\right) \cup\left(\frac{15}{32}, 1\right] \text { with } y=z=\frac{15}{32}, \\ \frac{129}{160} & \text { if } x=y=z=\frac{15}{32}\end{cases}
$$


which is lower semicontinuous. Thus, for all $x, y, z \in X$ with $x, y, z \neq 15 / 32$, there exist $u \in$ $F(x, y, z)=\left\{x^{2} / 4\right\}, v \in F(y, z, x)=\left\{y^{2} / 4\right\}$, and $w \in F(z, y, x)=\left\{z^{2} / 4\right\}$ such that

$$
\begin{aligned}
D(u, & F(u, v, w))+D(v, F(v, w, u))+D(w, F(w, v, u)) \\
& =\frac{x^{2}}{4}-\frac{x^{4}}{64}+\frac{y^{2}}{4}-\frac{y^{4}}{64}+\frac{z^{2}}{4}-\frac{z^{4}}{64} \\
& =\frac{1}{4}\left[\left(x+\frac{x^{2}}{4}\right)\left(x-\frac{x^{2}}{4}\right)+\left(y+\frac{y^{2}}{4}\right)\left(y-\frac{y^{2}}{4}\right)+\left(z+\frac{z^{2}}{4}\right)\left(z-\frac{z^{2}}{4}\right)\right] \\
& \leq \frac{1}{4}\left[\left(x+\frac{x^{2}}{4}\right) d(x, u)+\left(y+\frac{y^{2}}{4}\right) d(y, v)+\left(z+\frac{z^{2}}{4}\right) d(z, w)\right] \\
& \leq \frac{1}{4} \max \left\{\left(x+\frac{x^{2}}{4}\right),\left(y+\frac{y^{2}}{4}\right),\left(z+\frac{z^{2}}{4}\right)\right\}[d(x, u)+d(y, v)+d(z, w)] \\
& <\frac{10}{12} \max \left\{\left(x-\frac{x^{2}}{4}\right),\left(y-\frac{y^{2}}{4}\right),\left(z-\frac{z^{2}}{4}\right)\right\}[d(x, u)+d(y, v)+d(z, w)] \\
& \leq \phi(d(x, u)+d(y, v)+d(z, w))[d(x, u)+d(y, v)+d(z, w)] .
\end{aligned}
$$

Hence, for all $x, y, z \in X$ with $x, y, z \neq 15 / 32$, the conditions (2.35) and (2.36) are satisfied. Analogously, one can easily show that conditions (2.35) and (2.36) are satisfied for the cases $(x, y \in[0,15 / 32) \cup(15 / 32,1]$ with $z=15 / 32)$ and $(x \in[0,15 / 32) \cup(15 / 32,1]$ and $y=z=$ $15 / 32$ ). For the last case, that is, $x=y=z=15 / 32$, we assume that $u=v=w=15 / 96$, so it follows that

$$
[d(x, u)+d(y, v)+d(z, w)]=\frac{15}{16}>\frac{2}{3} .
$$

As a consequence, we get that

$$
\begin{aligned}
& \sqrt{\phi(d(x, u)+d(y, v)+d(z, w))}[d(x, u)+d(y, v)+d(z, w)] \\
& \quad=\sqrt{\frac{10}{16}} \frac{15}{16}<\frac{129}{160}=D(x, F(x, y, z))+D(y, F(y, z, x))+D(z, F(z, x, y)), \\
& D(u, F(u, v, w))+D(v, F(v, w, u))+D(w, F(w, v, u))=3\left|\frac{15}{96}-\frac{1}{4}\left(\frac{15}{96}\right)^{2}\right| \\
& \quad<\frac{10}{16} \frac{15}{16}=\phi(d(x, u)+d(y, v)+d(z, w))[d(x, u)+d(y, v)+d(z, w)] .
\end{aligned}
$$

Thus, we conclude that all the conditions of Theorem 2.7 are satisfied and $F$ admits a tripled fixed point $a=(0,0,0)$. 
Remark 2.9. If we replace the function $\phi$ with the following, we get the results again:

$$
\phi(t)= \begin{cases}\frac{7}{12} t & \text { if } t \in\left[0, \frac{3}{4}\right], \\ \frac{7}{16} & \text { if } t \in\left(\frac{3}{4}, \infty\right) .\end{cases}
$$

\section{References}

[1] S. B. Nadler Jr., "Multi-valued contraction mappings," Pacific Journal of Mathematics, vol. 30, pp. 475$488,1969$.

[2] J. T. Markin, "Continuous dependence of fixed point sets," Proceedings of the American Mathematical Society, vol. 38, pp. 545-547, 1973.

[3] I. Altun, "A common fixed point theorem for multivalued Æiriæ type mappings with new type compatibility," Analele Stiintifice ale Universitatii Ovidius Constanta, vol. 17, no. 2, pp. 19-26, 2009.

[4] L. Ćirić, "Fixed point theorems for multi-valued contractions in complete metric spaces," Journal of Mathematical Analysis and Applications, vol. 348, no. 1, pp. 499-507, 2008.

[5] L. Cirić, "Multi-valued nonlinear contraction mappings," Nonlinear Analysis: Theory, Methods $\mathcal{E}$ Applications, vol. 71, no. 7-8, pp. 2716-2723, 2009.

[6] Lj. B. Ćirić and J. S. Ume, “Common fixed point theorems for multi-valued non-self mappings," Publicationes Mathematicae Debrecen, vol. 60, no. 3-4, pp. 359-371, 2002.

[7] W.-S. Du, "Some generalizations of Mizoguchi-Takahashi's fixed point theorem," International Journal of Contemporary Mathematical Sciences, vol. 3, no. 25-28, pp. 1283-1288, 2008.

[8] G. Jungck and B. E. Rhoades, "Fixed points for set valued functions without continuity," Indian Journal of Pure and Applied Mathematics, vol. 29, no. 3, pp. 227-238, 1998.

[9] D. Klim and D. Wardowski, "Fixed point theorems for set-valued contractions in complete metric spaces," Journal of Mathematical Analysis and Applications, vol. 334, no. 1, pp. 132-139, 2007.

[10] N. Mizoguchi and W. Takahashi, "Fixed point theorems for multivalued mappings on complete metric spaces," Journal of Mathematical Analysis and Applications, vol. 141, no. 1, pp. 177-188, 1989.

[11] A. C. M. Ran and M. C. B. Reurings, "A fixed point theorem in partially ordered sets and some applications to matrix equations," Proceedings of the American Mathematical Society, vol. 132, no. 5, pp. 1435$1443,2004$.

[12] J. J. Nieto and R. Rodríguez-López, "Contractive mapping theorems in partially ordered sets and applications to ordinary differential equations," Order, vol. 22, no. 3, pp. 223-239, 2005.

[13] B. Samet and C. Vetro, "Coupled fixed point, F-invariant set and fixed point of N-order," Annals of Functional Analysis, vol. 1, no. 2, pp. 46-56, 2010.

[14] V. Berinde and M. Borcut, "Tripled fixed point theorems for contractive type mappings in partially ordered metric spaces," Nonlinear Analysis: Theory, Methods and Applications, vol. 74, no. 15, pp. 48894897, 2011.

[15] B. Samet and C. Vetro, "Coupled fixed point theorems for multi-valued nonlinear contraction mappings in partially ordered metric spaces," Nonlinear Analysis: Theory, Methods \& Applications, vol. 74, no. 12 , pp. $4260-4268,2011$. 


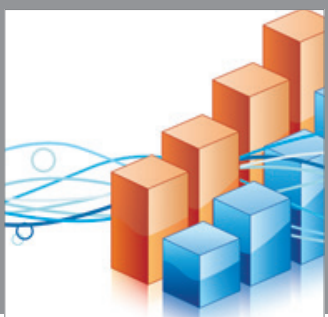

Advances in

Operations Research

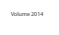

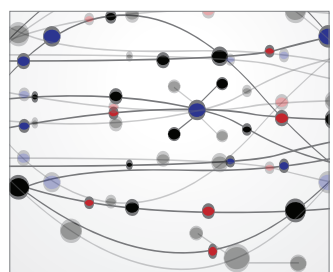

\section{The Scientific} World Journal
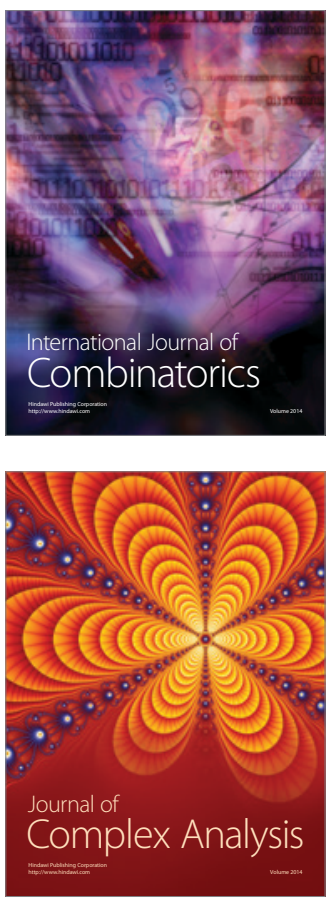

International Journal of

Mathematics and

Mathematical

Sciences
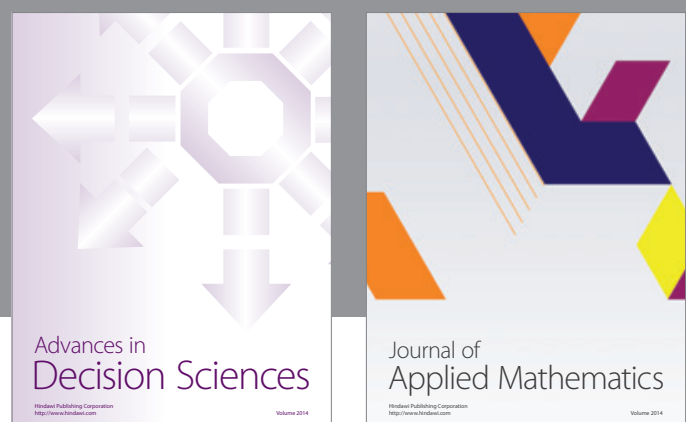

Journal of

Applied Mathematics
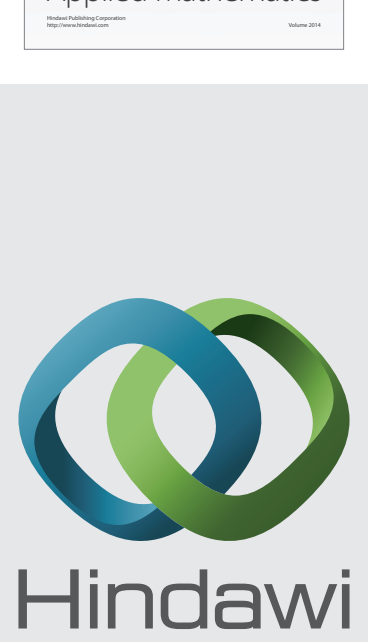

Submit your manuscripts at http://www.hindawi.com
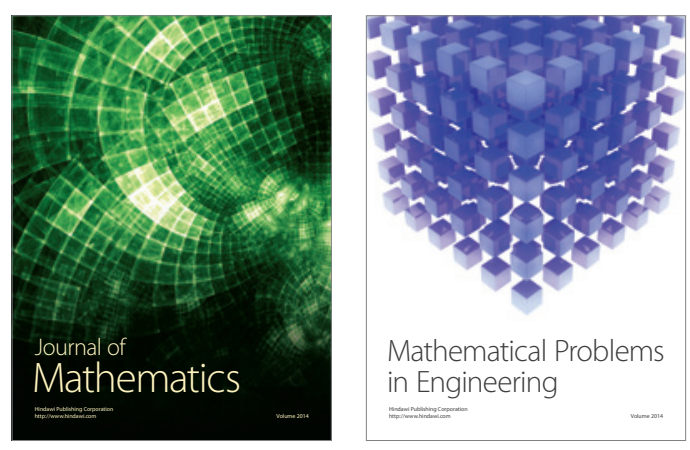

Mathematical Problems in Engineering
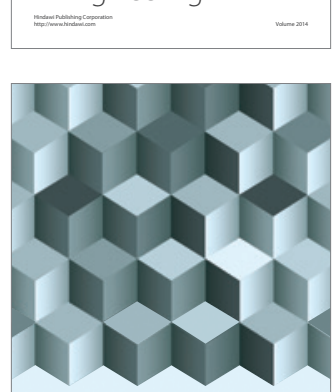

Journal of

Function Spaces
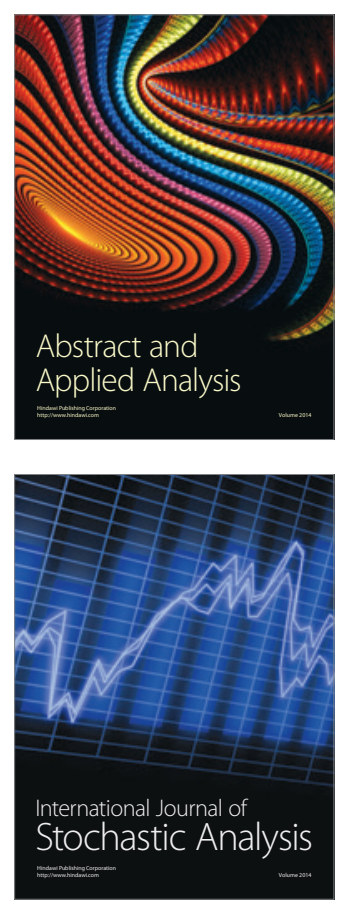

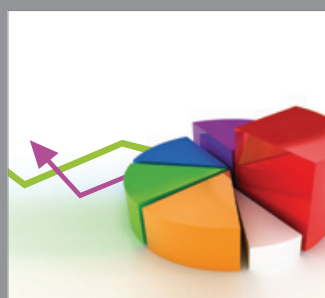

ournal of

Probability and Statistics

Promensencen
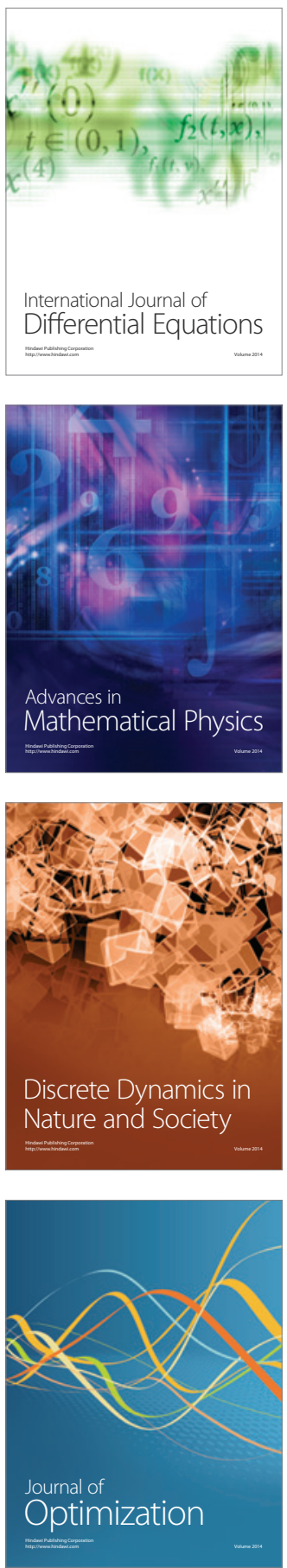